\title{
MODELLING OF THE DEPENDENCE OF TRAVEL FREQUENCY ON THE LENGTH AND DURATION OF A JOURNEY. IMPROVEMENT OF CITY PASSENGER TRANSPORT SYSTEMS
}

\author{
Jonas Butkevičius \\ Vilnius Gediminas Technical University, Transport Engineering Faculty, Transport Science Institute. \\ Plytinès g. 27, LT-2040 Vilnius, Lithuania.E-mail: tvl@ti.vtu.lt
}

Received 200206 02; accepted in 20021021

\begin{abstract}
The carried out research proved that the distribution of urban travel frequency according to the length and duration of a city journey can best be reflected by the Erlang k-distribution function. This function can be employed to predict time by work travel and the time of joumeys during the morning rush-hour. The results of the research done by the author show that over $30 \%$ of the residents of Vilnius and Kaunas reach work using public transport means. Their travel usually exceeds the normative length, i.e. over $40 \mathrm{~min}$. The obtained statistical data indicate that the current public transport systems in Vilnius and Kaunas are inadequate to meet the residents' needs. Therefore the author has suggested a whole complex of various measures to develop the system of the Lithuanian urban passenger transport. The main improvement measures have been proposed in accordance with the requirements for the passenger transport as defined by European Economic Community. The implementation of the proposed measures would allow to restore the prestige of the urban passenger transport and encourage its development under the existing market conditions.
\end{abstract}

Keywords: urban public transport, length and duration of a city journey, the Erlang distribution function, the development of public transport system.

\section{Introduction}

As the urban area is expanding, the length and duration of daily work travel using public transport means is increasing too.

The author's research results show that over $30 \%$ of the residents in Vilnius and Kaunas commute to work using public transport. The duration of their daily travel exceeds the normative length, i.e. lasts 40 minutes. This fact suggest an idea that the current systems of public transport in these cities are inadequate to meet their residents' needs. Thus it is a matter of utmost importance to introduce new means of public transport which will be more efficient in terms of transportation capacity as well as in terms of the communication speed. If becomes crucial to predict time for urban travel.

While predicting urban travel it is necessary to be aware of the distribution of travel frequency to the length and duration of a particular journey. For this purpose the author carried out modelling of the dependence of urban travel frequency on the length and duration of a particular journey. Also the author specified the longest possible as well as the average duration of urban travel for Lithuanian cities using public transport means. Moreover, he detailed the time of the maximum duration of urban work travel in Klaipeda.

The author has also proposed various measures to encourage the development of the passenger transport systems to be applied in Lithuanian cities.

\section{Modelling of the Dependence of Urban Travel Fre- quency on the Duration and Length of a Journey}

The results of the research carried out by foreign scientists as well as the author himself prove the fact that the distribution of urban travel frequency depending on the duration and length of an urban journey can best be reflected by the Erlang k-distribution function:

$$
F(a)=1-e^{-k a l} \sum_{n=0}^{k=1} \frac{(k a) n}{n l}
$$

there $k=\left(\frac{\ddot{x}}{S_{x}}\right)^{2}, \bar{x}-$ stands for the average meaning of quantity $x$, which is being analysed; $S_{x}$ is the standard probable error of quantity $x ; a$ - the ratio between quantity $x$, i.e. $a=x / x$.

The meanings of parameter $k$ are counted to a whole number. As parameter $k$ goes up, the Erlang k-distribution approaches the normal distribution [1]. Quantity $x$, here $l_{v}$ and $l$, are continuous quantities in general set. Analysing these quantities they are divided into separate intervals. It is expedient to specify such width that it would 
be equal to $1 / 5$ of the average meaning. Thus the best quantity to be used to carry out calculations for interval $a$ is 0.2 [2].

The theoretical distribution of travel frequency in accordance with a particular journey's length is shown in Fig 1.

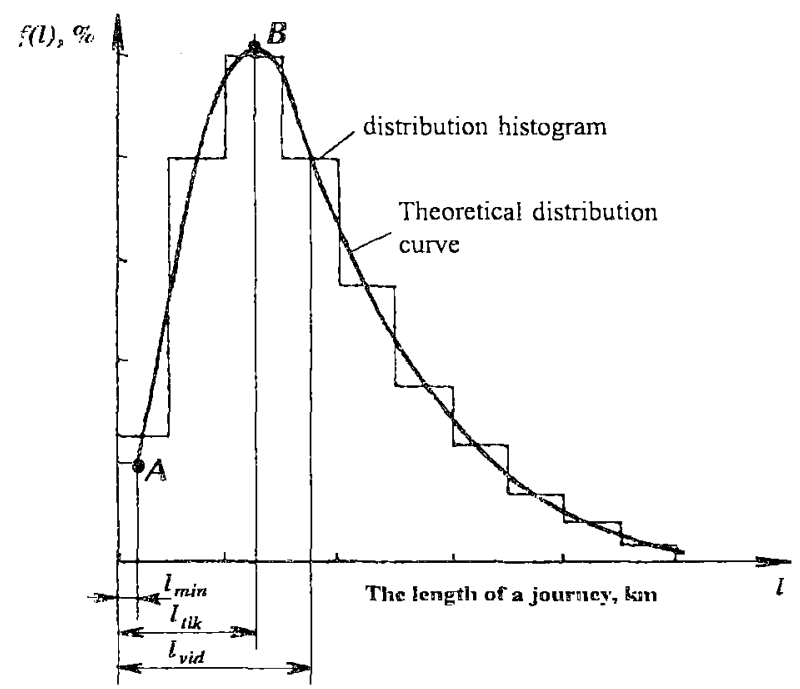

Fig 1. Theoretical distribution of travel frequency according to the length of a journey

Point $\mathrm{A}$ in Fig 1 specifies the minimum length of urban journey using public transport [3]. This length equals to the length of the shortest inter stop journey. Point $B$ defines the probable length of a journey which corresponds the biggest number of passengers:

$$
l_{\text {vid }}=\frac{\sum l i f(l) i}{\sum f(l i)}
$$

The theoretical distribution of travel frequency in accordance with the duration of an urban journey is provided in Fig 2.

Fig 3 shows the theoretical distribution of travel frequency according to the duration of an urban journey for three ways of travelling: using public transport, walking, the summative duration including both public transport means and legwork.

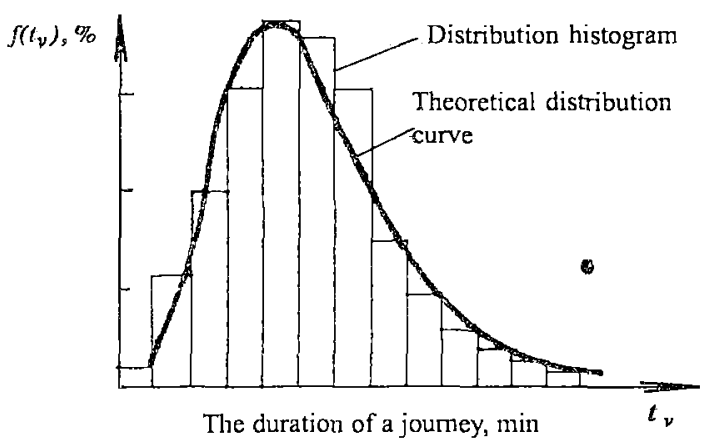

Fig 2. Theoretical distribution of travel frequency according to the duration of a joumey

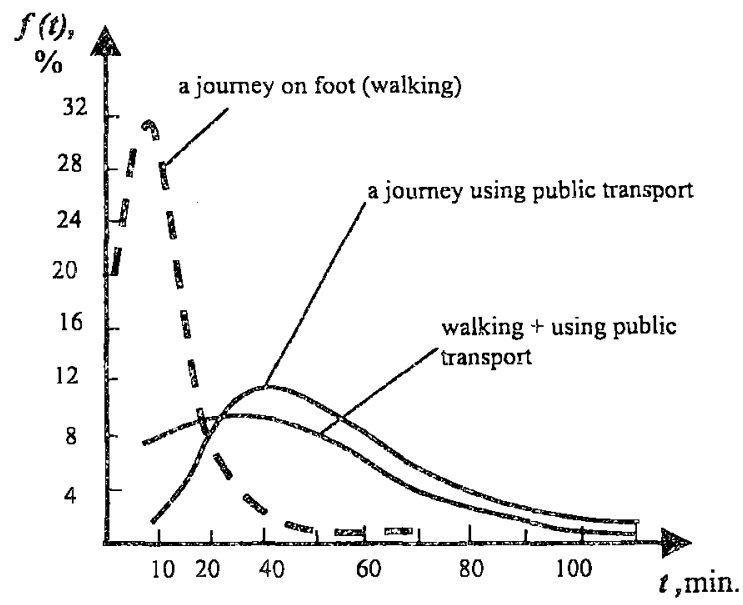

Fig 3. Theoretical distribution of travel frequency according to the duration of an urban journey

As the dependence of travel frequency on the duration and length of an urban journey can quite precisely be reflected by the Erlang k-distribution function. The latter can be used to predict the time for urban work travel as well as the public transport journeys during the morning rush-hour. Here it is essential to know parameter $k$. Usually the size of this parameter for cities with the population from 100 thousand to 1.5 million residents varies from 2 to $10[4,5]$.

The longest possible duration of work travel using public transport means in Vilnius (578.2 thousand residents) and in Kaunas ( 415.8 thousand residents) should not exceed 40 minutes and the average duration should not surpass 32 minutes. On analogy the maximum duration in Klaipeda with the population of 202.4 thousand people should not exceed 30 minutes whereas the average duration should not be more than 24 minutes.

The maximum duration of work travel (30 minutes) in Klaipeda would ideally consist of the total of the following time intervals:

1) walking from one's home till a public transport stop $-t_{p 1} \leq 5 \mathrm{~min}$

2) waiting for a public transport means $t_{l} \leq 2 \mathrm{~min}$.;

3) going to work by given public transport means $t_{\nu} \leq 20 \mathrm{~min}$;

4) one's workplace from a bus stop $t_{p 2} \leq 3 \mathrm{~min}$.

In such cities as Šiauliai (147.1 thousand people) and Panevéžys (133.6 thousand residents) the maximum duration of work travel including the four above-mentioned time intervals should not exceed 25 minutes and the average duration should be no longer than 20 minutes.

\section{The Proposals for the Development of Urban Pas- senger Transport Systems}

In order to develop the system of public transport in Lithuanian cities the author proposed to implement a whole complex of various measures, the most important of which are the following ones [6]: 
1) to ensure the same competitive conditions for all carriers organising competitions intended to grant a right to provide their services on fixed routes;

2) to legalise the relations between clients (local authorities) and carriers who have won a competition;

3) to finance a carrier who serves a particular fixed route. This financing should consist of compensations and subsidies. Besides marketability should also be foreseen. These three measures are based on the requirements for passenger transport defined by the European Economic Community;

4) to define the amount of passenger work which should be adequate to serve costs and carriers' financing;

5) to improve the management of city passenger transport following the Transport Management Models as implemented in Vilnius;

6) to ensure a systematic renewal of transport means;

7) to introduce fast public transport in Vilnius and Kaunas;

8) to optimise the performance of all means of public transport (buses, private buses, minibuses) as well as trolley-bus network in Vilnius and Kaunas;

9) to arrange the schedules of all means of public transport in accordance with passenger flows and evaluate the fluctuations of these flows in the course of a day, week or year;

10) to choose the best possible quantity of transport means to meet the fluctuations of passenger flaws;

11) to give priority to public transport in the entire system of the city communication network;

12) to introduce a single ticket system (including private vehicles) bearing in mind that the price of a ticket should be determined by the length of an urban journey;

13) to establish the central controller's office in Vilnius and Kaunas. The former will have to control and coordinate public transport traffic. All Vilnius trolleybuses have to be equipped with radio transmitters. Besides transmitters should be installed in minibuses as well as in private buses;

14) to differentiate the work starting time in separate big enterprises and organisations so that public transport can be evenly crowded in the morning rush-hour;

15) to introduce the "Park and Ride" system in the approaches to the centres of Vilnius and Kaunas building multi-storeyed car parking lots;

16) to improve the passenger infomation conveying systern;

17) to introduce separate traffic lanes for public transport;

18) to create a bank of the passenger transport data;

19) to train continually the staff of passenger service enterprises in order to improve the passenger service culture and make it more attractive to potential clients.

\section{Conclusions}

1. Predicting urban travel it is necessary to be aware of the distribution of travel frequency in accordance with the length and duration of an urban journey.

2. The results of the research carried out by foreign scientists as well as the author himself show that the distribution of urban travel frequency depending on the duration and length of a particular urban journey can best be reflected by the Erlang k-distribution function.

3. It is expedient to use the Erlang $\mathrm{k}$-distribution function to predict urban work travel as well as the public transport journeys during the morning rush-hour.

4. The results of the research carried out by the author highlight the fact that over $30 \%$ of the residents of Vilnius and Kaunas who reach work using public transport means travel over $40 \mathrm{~min}$. This data indicates that the current public transport systems in these cities are inadequate to meet the residents's needs.

5. The author proposed a whole set of measures to develop the public transport systems in Lithuanian cities. If these measures were implemented, they could bring a lot of positive changes:

- they would introduce market laws into the area of the public transport;

- they would ensure the same competitive conditions for different types of carriers;

- they would allow local authorities to obtain quality public transport service at a reasonable, not inflated price;

- they would eliminate the monopoly of big municipal (usually unprofitable) enterprises on the carriers' market;

- they would provide an opportunity for private carriers to integrate into the market;

- they would enable to reduce significantly the expenditures meant to finance the carriers.

\section{References}

1. Bhat C. R. Incorporating observed and unobserved heterogeneity in urban work travel mode choice modeling. Transportation Science, 2000, Vol 34, p 228-239.

2. Toth P.; Vigo G. Heuristic algorithms for the handicapped persons transportation problem. Transportation Science, 1997, Vol 31, p 60-71.

3. Friesz T.; Bernstein D.; Stough R. Dynamic Systems. Variational inequalities and control theoretic models for predicting time - varying urban network flows. Transportation Science, 1996, Vol 30, p 14-31.

4. Sans B.; Milot L. Performability of a congested urban transportation network when accident information is available. Transportation Science, 1999, Vol 33, p 68-79.

5. Sumi T.; Matsumoto Y.; Miyaki Y. Departure time and route choise of commuters on mass transit systems. Transport Research, 1990, Vol 248, No 4, p 247-262.

6. Butkevičius J. Rationalization of bus networks in Lithuania cities. In: XXI Meeting of bus coach experts, Hungary, Budapest, 1990, p 227-229. 